\title{
Determination of ETS1 gene single nucleotide polymorphism in Iranian patients with ankylosing spondylitis
}

\author{
Maryam Masoumi ${ }^{1}$, Mahdi Mahmoudi ${ }^{1 *}$, Zahra Malekshahi ${ }^{1,2}$, Jafar Karami $^{1,2}$, Mahdi Vojdanian ${ }^{1}$, Ahmadreza \\ Jamshidi $^{*}$ \\ ${ }^{1}$ Rheumatology Research Center, Tehran University of Medical Sciences, Tehran, Iran \\ ${ }^{2}$ Immunology Department, School of Medicine, Tehran University of Medical Sciences, Tehran, Iran
}

\begin{abstract}
Ankylosing spondylitis (AS) is an inflammatory arthritis with unknown etiology. AS mostly affects the axial skeleton and peripheral joints. The genetic contribution is believed to be a major attributable reason of overall susceptibility to AS. ETS1, also known as the avian erythroblastosis virus E26 (v-ets) oncogene homolog-1 gene, is essential in the development of immune cells in both adaptive and innate immunity. This study investigated the association of single nucleotide polymorphisms (SNPs) in the ETS1 gene (rs1128334 and rs10893872) with ankylosing spondylitis in Iranian population. The study samples comprised 495 AS patients and 490 controls. All samples were selected from the Iranian population. Two SNPs were chosen from the ETS1 gene (rs1128334 and rs10893872), and their association with AS was examined by applying the Real-time PCR allelic discrimination method. The results showed no significant associations between rs1128334 and rs10893872 SNPs and the risk of AS. However, the association between rs10893872 and the Bath Ankylosing Spondylitis Functional Index (BASFI) was significant $(p=0.02)$ after Bonferroni correction, while BASFI was significantly increased in cases with $\mathrm{CT}$ in comparison to $\mathrm{CC}$ genotype. The results of this study on the Iranian population did not confirm the association of the ETS1 gene SNPs with AS susceptibility; however, the association was significant in Han Chinese populations. The diversity in results among different populations is common in gene association studies of multifactorial diseases. Further investigations will be needed to identify other risk variants of the ETS1 gene which are correlated with AS susceptibility.
\end{abstract}

Keywords: ankylosing spondylitis, ETS1, Single Nucleotide Polymorphism (SNP).

\section{Introduction}

Ankylosing spondylitis (AS) is an inflammatory rheumatologic disorder that primarily affects the spinal and, occasionally, peripheral joints. Inflammation and new bone formation, especially in the spine, can lead to severe disability and functional limitations [1]. It involves men three times more often than women. People of any age can develop AS, but it usually appears between the ages of 15 and 30 [2].

The etiopathogenesis of AS is not yet fully understood, but the pivotal role of genetic mechanisms has clearly been implicated by the strong association observed between disease risk and the human leukocyte antigen (HLA)-B27. HLA-B27 has been associated with risk of AS in approximately $70 \%$ of Iranian patients [3], while epidemiological investigations have demonstrated that nearly $90 \%$ of white AS patients in the United States and northern Europe harbor HLA-B27. Despite its strong association with AS, HLA-B27 may account for only $20 \%$ to $30 \%$ of the overall genetic risk of AS $[4,5]$.

Recent genome-wide association studies (GWASs) have identified several non-HLA loci associated with AS, including ERAP1, IL23R, KIF2IB, CYP2D6, and two intergenic regions at 2p15 and 21q22 chromosomes [6, 7].

ETS1 (known as avian erythroblastosis virus E26 ( vets) oncogene homolog-1 gene) knockout mice have a different pattern of deficiency in their immunologic pathways [8]. In adult humans, the ETS1 gene is highly expressed mainly in immune tissues such as the thymus, spleen, and lymph nodes [9]. The association of this gene with SLE diseases has been documented in several studies [10-12]. GWASs of an Asian population revealed two susceptible SNPs, rs1128334 and rs10893872, for systemic lupus erythematosus (SLE) which had been previously reported as susceptible SNPs for this disease [13-15]. ETS1 as a non-HLA gene has

\footnotetext{
* Corresponding Authors: Mahdi Mahmoudi and Ahmadreza Jamshidi, Emails: mahmoudim@tums.ac.ir and jamshida@tums.ac.ir, Tel-fax: +98 2188220067
}

Received: 01 May 2017; Accepted: 15 May 2017 
been associated with the proneness to AS, and the rs1128334 SNP of this gene was strongly associated with AS risk in Han Chinese people [7]. Given the essential role of the ETS1 gene in the pathogenesis of autoimmune diseases and its frequently observed association with these diseases [16, 17], this study aimed to examine the association of the ETSI gene rs1128334 and rs10893872 SNPs with AS risk in an Iranian population.

\section{Material and Methods}

\section{Patients and controls}

The study group comprised 495 unrelated AS patients who were enrolled consecutively from the outpatient rheumatology clinic of Shariati Hospital, Tehran, Iran and 490 ethnically matched healthy controls (Table 1). The patient group consisted of 389 men and 106 women aged $38.3 \pm 10.4$ years who met the modified New York criteria for AS [18]. The mean age of the 490 healthy controls (104 females and 386 males) was 38.1 10.6 years, and they had neither an autoimmune disorder nor spondyloarthropathies. All participants in the study were from the Iranian population, and they all signed an informed consent form for participation in this study. AS patients were evaluated for disease severity and functional abilities by a protocol based on the Assessment of Spondyloarthritis International Society (ASAS) core set [19], which consists of disease activity by Bath Ankylosing Spondylitis Disease Activity Index (BASDAI) [20]; damage or deformity of the spine by Bath Ankylosing Spondylitis Metrology Index (BASMI) [21]; function by Bath Ankylosing Spondylitis Functional Index (BASFI) [22]; Bath Ankylosing Spondylitis Global Index (BAS-G); and pain score. Validated Persian versions of the BASFI and BASDAI questionnaires have been provided in the authors' previous studies [23]. To assess the quality of life, the Ankylosing Spondylitis Quality of Life (ASQoL) questionnaire was used [24]. This project was approved by the Human Research Ethics Committee of Tehran University of Medical Sciences.

\section{SNP genotyping}

Blood samples from cases and controls were collected in EDTA tubes, and genomic DNA was extracted using the phenol-chloroform method [25]. For genotyping the rs1128334 and rs10893872 SNPs, allelic discrimination approach was utilized using TaqMan MGB-based Realtime PCR (Applied Biosystems, Foster City, CA, USA). Genotyping was performed by approximately $30 \mathrm{ng}$ of the genomic DNA of each sample according to the manufacturer's protocols provided by Applied Biosystems. PCR was carried out using $5 \mu \mathrm{l}$ of the TaqMan Genotyping master mix (PN, 4371355), $0.25 \mu \mathrm{l}$ of TaqMan Genotyping assay mix (PN, 4351376), 0.25 $\mu \mathrm{l}$ of distilled water, and $4.5 \mu \mathrm{l}$ of genomic DNA in 10$\mu \mathrm{l}$ reaction volumes.

\section{Statistical analysis}

The statistical package SPSS version 22 (SPSS Inc., Chicago, IL, USA) was used for analysis. Chi-square test was applied to assess genotype and allele frequencies between patients and controls. The genotype and allele distributions were determined in each group, and odds ratios (OR) with $95 \%$ confidence intervals $(95 \%$ CI) were calculated. The genotype distributions of rs1128334 and rs10893872 were tested for deviation from the Hardy-Weinberg equilibrium in controls [26]. To adjust for multiple comparisons, the Benjamini-Hochberg method was used to control the false discovery rate (FDR) [27]. SHEsis online software was used for haplotype construction, genotype analysis, linkage disequilibrium, and the Hardy-Weinberg equilibrium (HWE) [28].

Table 1. Ethnic groups

\begin{tabular}{lcccc}
\hline \multirow{2}{*}{ Ethnic } & \multicolumn{2}{c}{ Case } & \multicolumn{2}{c}{ Control } \\
& Count & Percent & Count & Percent \\
\hline Fars & 222 & 44.8 & 237 & 48.4 \\
Turk & 138 & 27.9 & 133 & 27.1 \\
Kurd & 56 & 11.3 & 50 & 10.2 \\
Lor & 42 & 8.6 & 37 & 7.6 \\
Other & 37 & 7.4 & 33 & 6.7 \\
Total & 495 & $100 \%$ & 490 & $100 \%$ \\
\hline
\end{tabular}

\section{Results}

The current research aimed to genotype two SNPs (rs1128334 and rs10893872) in 495 AS patients and 490 healthy controls. No significant deviation from HWE was found in the control group. Analysis results did not show any significant association between the rs 1128334 and rs10893872 SNPs of the ETS1 gene and risk of AS in the Iranian population. There was no significantly different distribution of either allele or genotype between AS patients and healthy subjects (Table 2). Furthermore, there was no significant association in haplotype frequencies between the case and control groups (Table 3). Next, the association between the two genotyped SNPs with clinical manifestations, namely BASMI, BASFI, BASDAI, ASQOL and NRSpain was investigated through the ANNOVA and Post-Hoc tests (Table 4). After ANNOVA test, associations between BASMI, and BASFI with rs10893872 were significant 
( $p=0.04, p=0.03$ respectivity). With Post-Hoc analysis only BASFI score was significantly different among AS patients with CC, CT, and TT genotypes of rs 10893872 SNP $(p=0.02)$. BASFI was significantly increased in AS patients with the rs10893872 CT genotype in comparison with those who had the rs10893872 CC genotype after adjustment with the Bonferroni method (Table 4).

\section{Discussion}

Several GWASs have identified numerous genetic factors influencing susceptibility in the risk of autoimmune disease. In the current study, one of the non-HLA loci, which was already observed to be contributing to AS susceptibility, was investigated. The first member of the ETS gene family was V-Ets, and it was identified as a fusion oncogene of the avian transforming retrovirus E26 that induces both erythroblastic and myeloblastic leukemia in chickens
[29].

The ETS1 gene encodes protein C-ets-1 which is a member of the ETS family of transcription factors. Most of the ETS family proteins have the ETS domain in their N-terminal regions, which can bind to DNA by the third a-helix at the helix-turn-helix structure of the ETS domain [9]. Moreover, ETS family proteins interact with other transcription factors, so they can act as regulators on gene expression. They regulate many important processes in cell life, such as mitosis, development, and death [30].

Some studies have revealed its developmental role even in immune cells. As an example, ETS1 is involved in signal transduction pathways during $\mathrm{T}$ cell differentiation, playing a role in the stimulation of an intense response to presented peptides [30]. Furthermore, the presence of ETS1 has essential impacts on B cell development and regular immunoglobulin pattern production [16].

Table 2. Allele and genotype distribution of ETS1 in ankylosing spondylitis (AS) patients and healthy controls

\begin{tabular}{|c|c|c|c|c|c|}
\hline dbSNP & Alleles/genotypes & $\begin{array}{c}\text { AS }(n=495) \\
N(\%)\end{array}$ & $\begin{array}{c}\text { Control }(n=490) \\
N(\%)\end{array}$ & $p$ & OR $(95 \% \mathrm{CI})$ \\
\hline \multirow{5}{*}{ rs10893872 } & $\mathrm{C}$ & $514(52)$ & $478(49)$ & 0.2 & $1.1(0.9-1.3)$ \\
\hline & $\mathrm{T}$ & $476(48)$ & $494(51)$ & 0.2 & $0.9(0.7-1.1)$ \\
\hline & $\mathrm{CC}$ & $130(26.3)$ & $122(24.8)$ & 0.6 & $1.08(0.8-1.4)$ \\
\hline & $\mathrm{CT}$ & $256(51.8)$ & $234(47.8)$ & 0.2 & $1.1(0.9-1.5)$ \\
\hline & $\mathrm{TT}$ & 109 (21.9) & $134(27.4)$ & 0.06 & $0.7(0.5-1.1)$ \\
\hline HWE & \multicolumn{5}{|c|}{0.51} \\
\hline \multirow{5}{*}{ rs1128334 } & $\mathrm{C}$ & 867 (87.6) & 878 (89.6) & 0.15 & $0.8(0.6-1.1)$ \\
\hline & $\mathrm{T}$ & $123(12.4)$ & $102(10.4)$ & 0.15 & $1.2(0.9-1.6)$ \\
\hline & $\mathrm{CC}$ & $420(84.8)$ & $393(80.3)$ & 0.56 & $1.1(0.8-1.5)$ \\
\hline & $\mathrm{CT}$ & $71(14.4)$ & $92(18.8)$ & 0.06 & $0.7(0.5-1.1)$ \\
\hline & $\mathrm{TT}$ & $4(0.8)$ & $5(0.9)$ & 0.7 & $0.8(0.2-2.9)$ \\
\hline HWE & \multicolumn{5}{|c|}{0.78} \\
\hline
\end{tabular}

AS, ankylosing spondylitis; $p \leq 0.025$ was statistically significant after Bonferroni correction; HWE, Hardy-Weinberg equilibrium; OR, odds ratio; CI, confidence interval.

Table 3. Haplotype analysis of rs10893872 and rs1128334 in ankylosing spondylitis (AS) patients and healthy controls

\begin{tabular}{cccccc}
\hline Haplotypes & Case (freq) & Control (freq) & Chi $^{2}$ & $\boldsymbol{p}$ & Odds Ratio (95\% CI) \\
\hline C C & $271(52.7)$ & $215(48.2)$ & 1.95 & 0.163 & $1.20(0.93-1.54)$ \\
T C & $202(39.3)$ & $185(41.5)$ & 0.47 & 0.492 & $0.91(0.70-1.18)$ \\
T T & $41(8)$ & $46(10.3)$ & 1.58 & 0.208 & $0.75(0.48-1.17)$ \\
\hline
\end{tabular}

* Haplotypes with frequency more than 0.03 were selected for haplotype analysis 
Table 4. Association of ETS1 gene rs10893872 and rs1128334 genotypes with various clinical features of the 495 AS patients

\begin{tabular}{|c|c|c|c|c|c|c|}
\hline Characteristic & $\begin{array}{c}\text { rs10893872 } \\
\text { CC }\end{array}$ & $\begin{array}{c}\text { rs10893872 } \\
\text { CT }\end{array}$ & $\begin{array}{c}\text { rs10893872 } \\
\text { TT }\end{array}$ & $p$ & Post-Hoc & Corrected $p^{*}$ \\
\hline \multirow{3}{*}{ BASDAI } & \multirow{3}{*}{$4.15 \pm 2.15$} & \multirow{3}{*}{$4.82 \pm 2.47$} & \multirow{3}{*}{$4.81 \pm 2.09$} & \multirow{3}{*}{0.11} & CC vs. CT & 0.14 \\
\hline & & & & & CC vs. TT & 0.31 \\
\hline & & & & & CT vs. TT & 1.00 \\
\hline \multirow{3}{*}{ BASFI } & \multirow{3}{*}{$3.24 \pm 2.36$} & \multirow{3}{*}{$4.21 \pm 2.62$} & \multirow{3}{*}{$3.95 \pm 2.50$} & \multirow{3}{*}{0.03} & CC vs. CT & 0.02 \\
\hline & & & & & CC vs. TT & 0.34 \\
\hline & & & & & CT vs. TT & 1.00 \\
\hline \multirow{3}{*}{ BASMI } & \multirow{3}{*}{$3.59 \pm 1.65$} & \multirow{3}{*}{$4.13 \pm 2.05$} & \multirow{3}{*}{$4.36 \pm 1.64$} & \multirow{3}{*}{0.04} & CC vs. CT & 0.14 \\
\hline & & & & & CC vs. TT & 0.06 \\
\hline & & & & & CT vs. TT & 1.00 \\
\hline \multirow{3}{*}{ ASQoL } & \multirow{3}{*}{$6.61 \pm 4.44$} & \multirow{3}{*}{$8.32 \pm 5.48$} & \multirow{3}{*}{$7.67 \pm 5.03$} & \multirow{3}{*}{0.07} & CC vs. CT & 0.07 \\
\hline & & & & & CC vs. TT & 0.75 \\
\hline & & & & & CT vs. TT & 1.00 \\
\hline \multirow{3}{*}{ NRSPain } & \multirow{3}{*}{$5.609 \pm 0.66$} & \multirow{3}{*}{$5.58 \pm 0.47$} & \multirow{3}{*}{$5.42 \pm 0.71$} & \multirow{3}{*}{0.18} & CC vs. CT & 0.42 \\
\hline & & & & & CC vs. TT & 0.24 \\
\hline & & & & & CT vs. TT & 1.00 \\
\hline Characteristic & $\begin{array}{c}\text { rs1128334 } \\
\text { CC } \\
\end{array}$ & $\begin{array}{c}\text { rs1128334 } \\
\text { CT } \\
\end{array}$ & $\begin{array}{c}\text { rs1128334 } \\
\text { TT } \\
\end{array}$ & $p$ & Post-Hoc & Corrected $p^{*}$ \\
\hline & & & & & CC vs. CT & 1.00 \\
\hline BASDAI & $4.62 \pm 2.37$ & $4.87 \pm 2.41$ & $5.75 \pm 0.91$ & 0.68 & CC vs. TT & 1.00 \\
\hline & & & & & CT vs. TT & 1.00 \\
\hline & & & & & CC vs. CT & 1.00 \\
\hline BASFI & $3.88 \pm 2.61$ & $3.99 \pm 2.43$ & $4.95 \pm 0.77$ & 0.82 & CC vs. TT & 1.00 \\
\hline & & & & & CT vs. TT & 1.00 \\
\hline & & & & & CC vs. CT & 0.93 \\
\hline BASMI & $4.02 \pm 1.89$ & $4.37 \pm 1.94$ & $5.00 \pm 0.84$ & 0.47 & CC vs. TT & 1.00 \\
\hline & & & & & CT vs. TT & 1.00 \\
\hline & & & & & $\mathrm{CC} v s . \mathrm{CT}$ & 1.00 \\
\hline ASQoL & $7.71 \pm 5.07$ & $8.28 \pm 5.95$ & $6.00 \pm 5.65$ & 0.74 & CC vs. TT & 1.00 \\
\hline & & & & & CT vs. TT & 1.00 \\
\hline & & & & & CC vs. CT & 1.00 \\
\hline NRSPain & $9.07 \pm 5.77$ & $9.00 \pm 4.58$ & $8.50 \pm 3.53$ & 0.98 & $\mathrm{CC} v s . \mathrm{TT}$ & 1.00 \\
\hline & & & & & CT vs. TT & 1.00 \\
\hline
\end{tabular}

$* p$ value correction by Bonferroni method.

In addition to the adaptive immune response, ETS1 plays some pivotal roles in innate immunity, such as macrophage activation, NK cell and granulocyte differentiation [31, 32]. Based on a GWAS by Han et al., the ETS1 was identified as a risk factor for SLE. This study reported the association of some variants of the ETS1 gene including rs1128334, rs4937333, and rs6590330 with SLE [33]. Further studies examined the association of ETS1 gene rs11221332 SNP in Caucasian subjects and a Chinese population with rheumatoid arthritis (RA), demonstrating significant relations in both mentioned diseases [34, 35]. In addition, the association of ETS1 gene rs11221332 SNP was observed with celiac disease in a European population [36]. The contribution of ETSI to AS susceptibility in
Han Chinese people was assessed through the evaluation of seven SNPs of ETS1, but only rs1128334 was significantly associated with AS [37]. The present study did not show any significant association between allele frequencies and genotype distributions of either rs1128334 or rs10893872 SNPs of the ETS1 gene and AS susceptibility in the Iranian population. The association between clinical symptoms including BASDAI, ASQOL, NRSpain, BASMI, and BASFI (Table 4) with genotype distributions in AS patients was analyzed. A significant correlation was observed between the BASFI score of AS patients and rs10893872 genotypes. The association of rs1128334 SNP with AS in the current research contrasted with the results of Shan et al. [7]. This discrepancy might be due 
to differences in sample size and ethnicity, which causes a diverse genetic background. Another conceivable explanation for this difference is patient exposure to various environmental factors, which is accompanied by different sets of clinical manifestations. Nonetheless, different findings should be noted, because it appeared that rs1128334 had a significant association with AS in the Han Chinese population, but it did not have in the Iranian population. The power of this study is the favorably large sample size. However, evaluation of a small number of SNPs might be the weak aspect of this research. Through the typical genetic analysis techniques, the identification of small effects of multiple SNPs was avoided. However, other approaches such as gene set analysis (GSA) may be advantageous in detecting additional genetic loci for complex disorders [38].

\section{Conclusion}

Overall, this study evaluated the ETS1 gene rs1128334 and rs10893872 SNPs in association with AS. No significant associations were detected with regard to the alleles and genotypes of both positions. However, the BASFI score was significantly increased in AS patients with the rs10893872 CT genotype in comparison with those who have the rs10893872 CC genotype. Further studies are needed to identify other involved polymorphisms and genetic risk factors contributing to AS disease in the Iranian population.

\section{Conflicts of interest}

The authors declare no conflicts of interest.

\section{Acknowledgments}

This work was supported by a research grant from the Deputy of Research, Tehran University of Medical Sciences, Tehran, Iran (Grant No. 93-03-41-24477).

\section{References}

1. Braun J, Sieper J. Ankylosing spondylitis. The Lancet 2007; 369(9570):1379-90. doi: org/10. 1016/S0140-6736(07)60635-7.

2. Gran JT, Husby G: The epidemiology of ankylosing spondylitis. In: Seminars in arthritis and rheumatism: 1993: Elsevier; 1993: 319-34. doi: 10. 1016/S0049-0172(05)80011-3.

3. Fallahi S, Mahmoudi $M$, Nicknam MH, Gharibdoost F, Farhadi E, Saei A. et al. Effect of HLA-B* 27 and its subtypes on clinical manifestations and severity of ankylosing spondylitis in Iranian patients. Iranian Journal of Allergy, Asthma and Immunology 2013; 12(4): 321.

4. Sánchez A, Szczypiorska M, Juanola $\mathrm{X}$, Bartolomé $\mathrm{N}$ Gratacós J, Zarco P. et al. Association of the intergenic single-nucleotide polymorphism rs10865331 (2p15) with ankylosing spondylitis in a Spanish population. The Journal of rheumatology 2010; 37(11): 2345-47. doi: 10.3899/jrheum. 100211.

5. Brown MA. Progress in the genetics of ankylosing spondylitis. Briefings in functional genomics 2011:elr023. doi: 10.1093/bfgp/elr023.

6. Evans DM, Spencer CC, Pointon JJ, Su Z, Harvey D, Kochan G. et al. Interaction between ERAP1 and HLA-B27 in ankylosing spondylitis implicates peptide handling in the mechanism for HLA-B27 in disease susceptibility. Nature genetics 2011; 43(8): 761-67. doi: 10. 1038/ng.873.

7. Shan S, Dang J, Li J, Yang Z, Zhao H, Xin Q. et al. ETS1 variants confer susceptibility to ankylosing spondylitis in Han Chinese. Arthritis research \& therapy 2014; 16(2): R87. doi: 10.1186/ar4530.

8. Wang D, John SA, Clements JL, Percy DH, Barton KP, GarrettSinha LA. Ets-1 deficiency leads to altered B cell differentiation, hyperresponsiveness to TLR9 and autoimmune disease. International immunology 2005; 17(9): 1179-91. doi: 10.1093/ intimm/dxh295.

9. Oikawa T, Yamada T. Molecular biology of the Ets family of transcription factors. Gene 2003; 303:11-34. Molecular biology of the Ets family of transcription factors.

10. Yang W, Shen N, Ye DQ, Liu Q, Zhang Y, Qian XX. et al. Genome-wide association study in Asian populations identifies variants in ETS1 and WDFY4 associated with systemic lupus erythematosus. PLoS Genet
2010; 6(2): e1000841. doi: 10 1371/journal.pgen.1000841.

11. Sullivan KE, Piliero LM, Dharia T, Goldman D, Petri MA. 3 polymorphisms of ETS1 are associated with different clinical phenotypes in SLE. Hum Mutat 2000; 16(1): 49-53. doi: 10.1002/1098-1004(200007) 16: 1<49::aid-humu9>3.0.co;2-z.

12. Zhong H, Li XL, Li M, Hao LX, Chen RW, Xiang K. et al. Replicated associations of TNFAIP3, TNIP1 and ETS1 with systemic lupus erythematosus in a southwestern Chinese population. Arthritis Res Ther 2011; 13(6):R186. doi: 10.1186/ar3514.

13. Han J-W, Zheng H-F, Cui Y, Sun L-D, Ye D-Q, Hu Z. et al. Genome-wide association study in a Chinese Han population identifies nine new susceptibility loci for systemic lupus erythematosus. Nature genetics 2009; 41(11): 1234-37. doi: 10. 1038/ng.472.

14. Cui Y, Sheng Y, Zhang X. Genetic susceptibility to SLE: recent progress from GWAS. Journal of autoimmunity 2013; 41: 25-33. doi: 10.1016/j.jaut. 2013.01.008

15. Zhang J, Zhang $\mathrm{Y}$, Zhang $\mathrm{L}$, Yang J, Ying D, Zeng S. et al. Epistatic Interaction between Genetic Variants in Susceptibility 
Gene ETS1 Correlates with IL-17 Levels in SLE Patients. Annals of human genetics 2013; 77(4): 344-50. doi: 10.1111/ahg.12018.

16. Wang D, John SA, Clements JL, Percy DH, Barton KP, GarrettSinha LA. Ets-1 deficiency leads to altered B cell differentiation, hyperresponsiveness to TLR9 and autoimmune disease. Int Immunol 2005; 17(9):1179-91. doi: 10.1093/intimm/dxh295.

17. Moisan J, Grenningloh R, Bettelli E, Oukka M, Ho IC. Ets-1 is a negative regulator of Th17 differentiation. J Exp Med 2007; 204(12): 2825-35. doi: 10.1084/ jem.20070994.

18. Linden SVD, Valkenburg HA, Cats A. Evaluation of diagnostic criteria for ankylosing spondylitis. Arthritis \& Rheumatology 1984; 27(4): 36168. doi:10.1002/art.1780270401.

19. van der Heijde D, van der Linden S, Bellamy N, Calin A, Dougados M, Khan MA. Which domains should be included in a core set for endpoints in ankylosing spondylitis? Introduction to the ankylosing spondylitis module of OMERACT IV. J Rheumatol 1999; 26(4): 945-7.

20. Garrett S, Jenkinson T, Kennedy LG, Whitelock H, Gaisford P, Calin A. A new approach to defining disease status in ankylosing spondylitis: the Bath Ankylosing Spondylitis Disease Activity Index. J Rheumatol 1994; 21(12): 2286-91.

21. Jones SD, Porter J, Garrett SL, Kennedy LG, Whitelock H, Calin A. A new scoring system for the Bath Ankylosing Spondylitis Metrology Index (BASMI). $\boldsymbol{J}$ Rheumatol 1995; 22(8): 1609.

22. Calin A, Garrett S, Whitelock $H$, Kennedy L, O'hea J, Mallorie P. et al. A new approach to defining functional ability in ankylosing spondylitis: the development of the Bath Ankylosing Spondylitis Functional Index. The Journal of rheumatology 1994; 21(12): 2281-85.

23. Bidad K, Fallahi S, Mahmoudi M, Jamshidi A, Farhadi E, Meysamie A. et al. Evaluation of the Iranian versions of the Bath Ankylosing Spondylitis Disease Activity
Index (BASDAI), the Bath Ankylosing Spondylitis Functional Index (BASFI) and the Patient Acceptable Symptom State (PASS) in patients with ankylosing spondylitis. Rheumatol Int 2012; 32(11): 3613-8. doi: 10.1007/s00296-0112186-2.

24. Fallahi S, Jamshidi AR, Bidad K, Qorbani M, Mahmoudi M. Evaluating the reliability of Persian version of ankylosing spondylitis quality of life (ASQoL) questionnaire and related clinical and demographic parameters in patients with ankylosing spondylitis. Rheumatology international 2014; 34(6): 803-09. doi: 10. 1007/s00296-013-2888-8.

25. Roe BA, Crabtree J, Khan A. Methods for DNA isolation. Part III. Protocols for recombinant DNA isolation, cloning, and sequencing [Internet edition] Norman, OK: University of Oklahoma 1995: 2488-98.

26. Balding DJ. A tutorial on statistical methods for population association studies. Nat Rev Genet 2006; 7(10):781-91. doi: 10.1038/nrg1916.

27. Benjamini Y, Hochberg Y. Controlling the false discovery rate: a practical and powerful approach to multiple testing. Journal of the Royal Statistical Society Series B (Methodological) 1995: 289-300.

28. Yong $\mathrm{Y}$, Lin $\mathrm{H}$. SHEsis, a powerful software platform for analyses of linkage disequilibrium, haplotype construction, and genetic association at polymorphism loci. Cell research 2005; 15(2): 97-98. doi: 10.1038/sj.cr.7290272.

29. Leprince D, Gegonne A, Coll J, De Taisne C, Schneeberger A, Lagrou C. et al. A putative second cell-derived oncogene of the avian leukaemia retrovirus E26. 1983.

30. Gallant S, Gilkeson G. ETS transcription factors and regulation of immunity. Arch Immunol Ther Exp (Warsz) 2006; 54(3):149-63. doi: 10.1007/ s00005-006-0017-z.

31. Barton K, Muthusamy N, Fischer $\mathrm{C}$, Ting $\mathrm{C}-\mathrm{N}$, Walunas TL, Lanier
LL. et al. The Ets-1 transcription factor is required for the development of natural killer cells in mice. Immunity 1998; 9(4):555-63. doi: 10.1016/S10747613(00)80638-X.

32. Klemsz MJ, McKercher SR, Celada A, Van Beveren C, Maki RA. The macrophage and B cellspecific transcription factor PU. 1 is related to the ets oncogene. Cell 1990; 61(1): 113-24. doi: 10.1016/0092-8674(90)90219-5.

33. Han JW, Zheng HF, Cui Y, Sun LD, Ye DQ, Hu Z. et al. Genomewide association study in a Chinese Han population identifies nine new susceptibility loci for systemic lupus erythematosus. Nat Genet 2009; 41(11): 1234-7. doi: 10.1038/ng.472.

34. Chatzikyriakidou A, Voulgari PV, Georgiou I, Drosos AA. Altered sequence of the ETS1 transcription factor may predispose to rheumatoid arthritis susceptibility. Scand $J$ Rheumatol 2013; 42(1): 11-4. doi: $\quad 10.3109 / 03009742.2012$ 711367.

35. Zhang Y, Bo L, Zhang H, Zhuang C, Liu R. E26 TransformationSpecific-1 (ETS1) and WDFY Family Member 4 (WDFY4) Polymorphisms in Chinese Patients with Rheumatoid Arthritis. Int J Mol Sci 2014; 15(2): 2712-21. doi: 10.3390/ijms 15022712 .

36. Dubois PCA, Trynka G, Franke L, Hunt KA, Romanos J, Curtotti A. et al. Multiple common variants for celiac disease influencing immune gene expression. Nat Genet 2010; 42(4): 295-302. doi: 10.1038/ng. 543 .

37. Shan S, Dang J, Li J, Yang Z, Zhao $\mathrm{H}$, Xin Q. et al. ETS1 variants confer susceptibility to ankylosing spondylitis in Han Chinese. Arthritis Res Ther 2014; 16(2): R87. doi: 10.1186/ ar4530.

38. Fridley BL, Biernacka JM. Gene set analysis of SNP data: benefits, challenges, and future directions. European Journal of Human Genetics 2011; 19(8): 837. doi: 10.1038/ejhg.2011.57 